subtypes is jointly associated with RNA transcripts or FAIME scores with strong differences in relation to the geographical origin of samples; neutrophils emerged as the major determinant of gene expression in SSc-whole-blood samples. Conclusion: We discovered a set of differentially expressed genes and pathways that could be validated in two independent sets of SSc patients highlighting a number of deregulated molecular processes that have relevance for the pathogenesis of autoimmunity and SSc.

Figure:

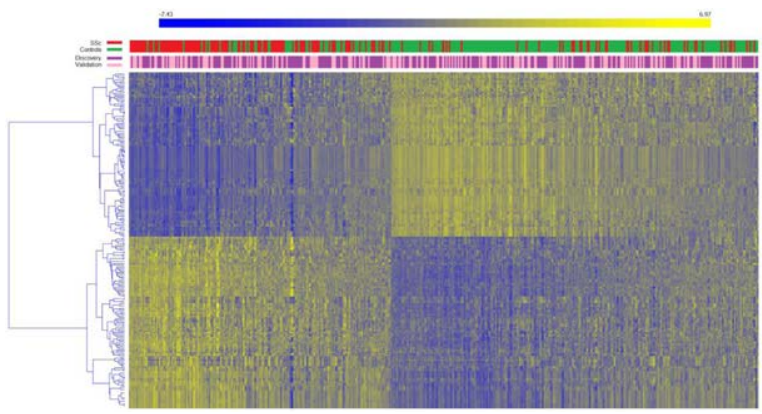

Acknowledgments: This work was supported by EU/EFPIA/Innovative Medicines Initiative Joint Undertaking PRECISESADS grant No. 115565.

Disclosure of Interests: Lorenzo Beretta Grant/research support from: Pfizer, Guillermo Barturen: None declared, Barbara Vigone: None declared, Chiara Bellocchi: None declared, Nicolas Hunzelmann: None declared, Ellen Delanghe: None declared, László Kovács: None declared, Ricard Cervera: None declared, Maria Gerosa: None declared, Rafaela Ortega Castro: None declared, Isabel Almeida: None declared, Divi Cornec: None declared, Carlo Chizzolini Consultant of: Boehringer Ingelheim, Roche, Jacques-Olivier Pers: None declared, Zuzanna Makowska Employee of: Bayer AG, Anne buttgereit Employee of: Bayer AG, Ralf Lesche Employee of: Bayer, Martin Kerick: None declared, Marta Alarcon-Riquelme: None declared, Javier Martin Ibanez: None declared DOI: 10.1136/annrheumdis-2020-eular.3788

\section{OP0138 \\ CLUSTERIN ASSOCIATES WITH DISEASE MECHANISMS AND INFLAMMATION IN MYOSITIS PATIENTS}

T. Kropackova ${ }^{1,2}$, L. Vernerová ${ }^{1}$, H. Štorkánová ${ }^{1,2}$, V. Horvathova ${ }^{1,2}$ M. Vokurková ${ }^{1}$, M. Klein ${ }^{1,2}$, S. Oreska ${ }^{1,2}$, M. Špiritović ${ }^{1}$, B. Heřmánkováa ${ }^{3}$, K. Kubinova ${ }^{1,2}$ L. Andres Cerezo ${ }^{1}$, O. Kryštůfková ${ }^{1,2}$, H. Mann ${ }^{1,2}, J^{\prime}$ Ukropec $^{4}$, B. Ukropcová ${ }^{4}$, J. Zámečník ${ }^{5}$, M. Tomčík ${ }^{1,2}$, J. Vencovský ${ }^{1,2}$, L. Šenolt ${ }^{1,2}$ ${ }^{1}$ Institute of Rheumatology, Prague, Czech Republic; ${ }^{2}$ First Faculty of Medicine, Charles University, Department of Rheumatology, Prague, Czech Republic; ${ }^{3}$ Faculty of Physical Education and Sport, Charles University, Department of Physiotherapy, Prague, Czech Republic; ${ }^{4}$ Biomedical Research Center, Slovak Academy of Sciences, Institute of Experimental Endocrinology, Bratislava, Slovakia (Slovak Republic); ${ }^{5}$ 2nd Medical School and University Hospital Motol, Charles University, Department of Pathology and Molecular Medicine, Prague, Czech Republic

Background: Idiopathic inflammatory myopathies (IIM, myositis) are a heterogeneous group of autoimmune muscle disorders characterized by skeletal muscle weakness and damage, inflammation and extramuscular manifestations. Recent findings suggest that immunological as well as nonimmunological processes, such as endoplasmic reticulum stress, hypoxia, mitochondrial and metabolic dysfunction are involved in the pathogenesis of IIMs [1]. Clusterin (CLU) has been reported to play a protective function in the development of tissue injury, inflammation and autoimmunity, and is involved in the maintenance of immune homeostasis [2]

Objectives: This study aimed to explore a potential involvement of the circulating levels and skeletal muscle expression of CLU in pathogenic mechanisms of IIM.

Methods: A total of 85 IIM patients and 86 healthy controls $(\mathrm{HC})$ were recruited. In addition, $20 \mathrm{IIM}$ patients and $21 \mathrm{HC}$ underwent a muscle biopsy. Circulating concentrations of CLU were measured by ELISA. Serum cytokine profile of patients and $\mathrm{HC}$ was assessed by Cytokine 27-plex Assay. Immunohistochemical localisation of CLU was assessed in $10 \mathrm{IIM}$ and 4 control muscle tissue specimens. The expression of CLU and myositis related cytokines in muscle tissue was determined by real-time PCR.

Results: We observed a significant increase of circulating CLU in all IIM patients compared to HC (86.2 (71.6-99.0) vs. 59.6 (52.6-68.4) $\mathrm{gg} / \mathrm{mL}, \mathrm{p}<0.0001)$. Moreover, CLU serum levels were positively correlated with myositis disease activity assessment (MYOACT) $(r=0.337, p=0.008)$, myositis intention-to-treat activity index (MITAX) $(r=0.357, p=0.004)$ and global disease assessment evaluated by physician $(r=0.309, p=0.015)$. In addition to that, a multivariate redundancy analysis revealed a combined effect of serum CLU and cytokine profile (represented by cytokines and chemokines known to be involved in IIM) on disease activity measures. In muscle tissue, CLU mRNA was significantly increased in IIM patients compared to controls $(p=0.032)$ and correlated with IL-1 $\beta(r=0.489$ $p=0.034), I L-6(r=0.581, p=0.009), \operatorname{TNF}(r=0.485, p=0.035)$ and PGC-1a $(r$ $=0.709, p=0.001)$ mRNA. Immunohistochemistry revealed CLU accumulation in the cytoplasm of regenerating myofibers.

Conclusion: Our results show an up-regulation of clusterin in circulation and skeletal muscle of IIM patients that associates with disease activity and inflammation, and its specific expression in regenerating myofibres. Based on our data and the known cytoprotective function of CLU we suggest an attempt of the organism to limit further muscle damage induced by myositis disease mechanisms.

References:

[1] Ernste FC, Reed AM. Idiopathic inflammatory myopathies: current trends in pathogenesis, clinical features, and up-to-date treatment recommendations. Mayo Clin Proc. 2013;88:83-105.

[2] Savkovic V, Gantzer H, Reiser U, Selig L, Gaiser S, Sack U, et al. Clusterin is protective in pancreatitis through anti-apoptotic and anti-inflammatory properties. Biochem Biophys Res Commun. 2007;356:431-7.

Acknowledgments: This work was supported by GAUK 534217 and the Ministry of Health of the Czech Republic grants nr. 16-33746A and 16-33574A.

Disclosure of Interests: None declared

DOI: 10.1136/annrheumdis-2020-eular.6237

OP0139 FUNCTIONAL EVALUATION OF THE SJÖGREN'S
SYNDROME AND SYSTEMIC LUPUS ERYTHEMATOSUS DDX6-CXCR5 RISK INTERVAL

M. M. Wiley ${ }^{1}$, B. Khatri ${ }^{1}$, K. L. Tessneer ${ }^{1}$, M. L. Joachims ${ }^{1}$, A. M. Stolarczyk ${ }^{1}$, A. Rasmussen ${ }^{1}$, S. J. Bowman ${ }^{2}$, L. Radfar ${ }^{3}$, R. Omdal ${ }^{4}$, M. Wahren-Herlenius ${ }^{5}$, B. M. Warner ${ }^{6}$, T. Witte ${ }^{7}$, R. Jonsson ${ }^{8}$, M. Rischmueller ${ }^{9}$, P. M. Gaffney ${ }^{1}$, J. A. James ${ }^{1}$, L. Ronnblom ${ }^{10}$, R. H. Scofield ${ }^{3}$, X. Mariette ${ }^{11}$, W. F. Ng ${ }^{12}$, K L. Sivils ${ }^{1}$, G. Nordmark ${ }^{10}$, B. Tsao ${ }^{13}$, C. Lessard ${ }^{1} .{ }^{1}$ Oklahoma Medical Research Foundation, Oklahoma City, United States of America; ${ }^{2}$ University Hospitals Birmingham NHS Foundation Trust, Birmingham, United Kingdom; ${ }^{3}$ University of Oklahoma, Oklahoma City, United States of America; ${ }^{4}$ University of Bergen Bergen, Norway; ${ }^{5}$ Karolinska Institute, Stockholm, Sweden; ${ }^{6}$ National Institute of Dental and Craniofacial Research, Bethesda, United States of America; ${ }^{7}$ Hannover Medical School, Hannover, Germany; ${ }^{8}$ Haukeland University Hospital, Bergen, Norway; ${ }^{9}$ University of Adelaide, Adelaide, Australia; ${ }^{10}$ Uppsala University, Uppsala, Sweden; ${ }^{11}$ Université Paris-Saclay, Le Kremlin Bicêtre, France; ${ }^{12}$ NHR Biomedical Research Centre, Newcastle upon Tyne, United Kingdom; ${ }^{13}$ Medical University of South Carolina, Charleston, United States of America

Background: Sjögren's Syndrome (SS) and Systemic Lupus Erythematosus (SLE) are distinct chronic, complex autoimmune diseases with shared characteristics such as autoantibodies, heightened interferons, and polyarthritis SS and SLE genome-wide association studies (GWAS) report strong associations with the DDX6-CXCR5 risk interval. DDX6 suppresses interferon stimulated gene expression and CXCR5 regulates $T$ cell functions implicated in autoimmunity.

Objectives: To identify functional variants that impact regulation in the DDX6CXCR5 interval.

Methods: Fine-mapping was done using ImmunoChip data from 3785 SLE 1916 SS cases and 6893 population controls of European ancestry that were imputed and tested for SNP-trait association. Bayesian statistics assigned posterior probabilities to SNPs and defined a credible set of risk variants. Bioinformatic analyses further prioritized variants with predicted functionality. Electrophoretic mobility shift assays (EMSAs) and luciferase expression were used to validate predicted SNPs in EBV transformed B (EBV B) cells.

Results: While some differences were observed, the overall SS and SLE association signals were similar. SNP-SS rs9736016 near CXCR5 and SNP-SLE rs76409436 near DDX6 were the most significant but did not show evidence of functionality. Bayesian statistics defined credible sets of variants in strong D' in common between both SS and SLE. Bioinformatics analyses (Haploreg, ReguIomeDB, ENCODE data, etc) further refined the credible set and identified $5 \mathrm{com}-$ mon SNPs with strong evidence of functionality in immune cell types: rs 4938572 rs4936443, rs57494551, rs7117261 and rs4938573. EMSAs showed a significant increase in protein binding to the risk allele of rs57494551 ( $p=0.0001)$, rs7117261 $(p=0.0001)$ and $r s 4938573(p=0.0003)$, but not the others, using nuclear lysates from EBV B cells. Luciferase vectors with a minimal promoter or no promoter were used to test for enhancer or promoter activity, respectively. To this end the rs57494551 risk allele exhibited a significant increase in enhancer activity $(p=0.0001)$. In contrast, the rs7117261 risk allele decreased enhancer activity 
$(p=0.018)$. The rs4938573 risk allele decreased enhancer $(p=0.043)$ and promoter $(p=0.024)$ activity. While $r s 7117261$ or $r 54938573$ were not reported in eQTL databases, GTex data reported rs57494551 as an eQTL that alters DDX6 expression in whole blood ( $\mathrm{p}=1.8 \mathrm{E}-7)$. Additionally, these functional SNPs have been associated with looping events to several proximal promoters in nearby genes in immune cells.

Conclusion: SS and SLE have similar genomic architecture across the DDX6 CXCR5 risk interval. Multiple variants in the credible set exhibited allele specific changes in protein binding, as well as modified enhancer activity, promoter activity or both. Ongoing studies will use Cas9 in EBV B cells to determine which other loci are within the local regulatory network.

Disclosure of Interests: Mandi M Wiley: None declared, Bhuwan Khatri: None declared, Kandice L Tessneer: None declared, Michelle L Joachims: None declared, Anna M Stolarczyk: None declared, Astrid Rasmussen Speakers bureau: Novartis, ThermoFischer, Simon J. Bowman Consultant of: Astrazeneca, Biogen, BMS, Celgene, Medimmune, MTPharma, Novartis, Ono, UCB, xtlbio, Glapagos, Speakers bureau: Novartis, Lida Radfar: None declared, Roald Omdal: None declared, Marie Wahren-Herlenius: None declared, Blake M Warner: None declared, Torsten Witte: None declared, Roland Jonsson: None declared, Maureen Rischmueller: None declared, Patrick M Gaffney: None declared, Judith A. James Grant/research support from: Progentec Diagnostics, Inc, Consultant of: Abbvie, Novartis, Jannsen, Lars Ronnblom Grant/research support from: AZ, Speakers bureau: AZ, R Hal Scofield Grant/research support from: Pfizer, Xavier Mariette: None declared, Wan-fai Ng: None declared, Kathy L Sivils: None declared, Gunnel Nordmark: None declared, Betty Tsao: None declared, Christopher Lessard: None declared

DOI: 10.1136/annrheumdis-2020-eular.3935

\section{OP0140 DYSREGULATED EXPRESSION OF THE LONG NON- CODING RNA, LINC01871, IMPLICATED IN SJÖGREN'S SYNDROME PATHOGENESIS}

M. L. Joachims ${ }^{1}$, B. Khatri ${ }^{1}$, K. L. Tessneer ${ }^{1}$, A. M. Stolarczyk ${ }^{1}$, G. B. Wiley ${ }^{1}$ A. Rasmussen ${ }^{1}$, J. Guthridge ${ }^{1}$, J. A. James ${ }^{1}$, R. H. Scofield ${ }^{2}$, K. L. Sivils ${ }^{1}$, I. Adrianto ${ }^{3}$, C. Lessard $1 .{ }^{1}$ Oklahoma Medical Research Foundation, Oklahoma City, United States of America; ${ }^{2}$ University of Oklahoma, Oklahoma City, United States of America; ${ }^{3}$ Henry Ford Health System, Detroit, United States of America

Background: Sjögren's syndrome (SS) is a chronic, heterogenous autoimmune disease characterized by inflammatory destruction of the exocrine glands. Long non-coding RNAs (IncRNAs) have emerged as a functionally diverse class of non-protein coding RNA (ncRNA) with increasing implications in interferon signaling, immune cell regulation, and autoimmune disease pathology. The potentia role of IncRNAs in SS pathogenesis is unknown.

Objectives: To identify and characterize candidate IncRNAs with potential relevance to SS pathology.

Methods: RNA-seq was used on whole blood from SS patients $(n=30$ antibody negative $\left(\mathrm{Ro}^{-}\right) ; \mathrm{n}=27$ antibody positive $\left(\mathrm{Ro}^{+}\right)$) and healthy controls $(\mathrm{HC}, \mathrm{n}=27)$ to identify differentially expressed (DE) IncRNAs (log2 fold change (FC) $\geq 2$ or $\leq$ $\left.0.5 ; p_{\text {adj }}<0.05\right)$. Bioinformatic and pathway analyses were used to predict IncRNA function. In vitro time course experiments in HSB2 T cell lymphoblasts stimulated with PMA/lonomycin (PMA/I) or type I interferon (IFN) were used to assess biological relevance. LINC01871 function was further investigated by RNA-seq on a single cell clone of HSB2 with confirmed CRISPR-targeted LINC01871 deletion (LINC01871 $1^{-/-}$).

Results: We identified a total of 1054 unique DE ncRNAs between $\mathrm{Ro}^{+}$, Ro- and/ or a combined analysis relative to $\mathrm{HC}$; of these, 45 ( 1 long intergenic ncRNA (lincRNA), 1 antisense, 43 pseudogenes) were overexpressed in all 3 SS subsets. To begin investigating the function of the previously undescribed lincRNA LINC01871 (SS ${ }^{\text {Ro- }}: F C=2.85 ; \mathrm{p}=1.1 \times 10^{-4}$ ), we performed a correlation analysis of the $S^{R o-}$ transcriptome, which found several co-expressed protein coding RNAs involved in immune regulation (THEMIS, TBX21, IL10RA, IL2RB, among many others). Similarly, Ingenuity Pathway Analysis of the SS transcriptome compared to $\mathrm{HC}$, as well as several gene ontology enrichment analyses of publicly available RNA expression correlation databases, identified shared immune-related pathways including cytotoxic $T$ cell, natural killer cell, and T cell regulation. To further study the role of LINC01871 in cytotoxic T cells, we used qRT-PCR to resolve the effects of PMA/I or type I IFN stimulation on LINC01871 expression in the T lymphoblastoid HSB2 cells. LINC01871 expression was downregulated after PMA/I stimulation, but unchanged with type I IFN stimulation. To explore the regulatory function of LINC01871 in T cells, we targeted LINC01871 in HSB2 cells

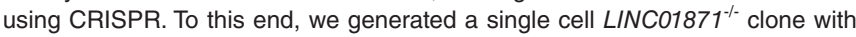
no RNA expression by qPCR and confirmed homozygous deletion using DNA

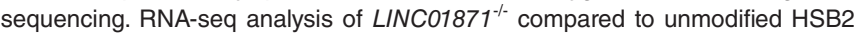
cells identified 1166 DE transcripts. Pathway analyses clustered the DE transcripts into similar immune regulatory, cytotoxic and $\mathrm{T}$ cell pathways identified in $S^{\text {Ro- }}$ whole blood RNA-seq and publicly available RNA-seq databases. Further, several prominent $\mathrm{T}$ cell regulatory transcripts that exhibited correlated upregulation with LINC01871 in SS ${ }^{\text {Ro- }}$ whole blood RNA-seq also demonstrated downregulation after LINC01871 deletion: CD109 (FC=-9.7; $\left.\mathrm{p}_{3}=5.3 \times 10^{-16}\right), I L 22$ $\left(F C=-8.1 ; p_{a d j}=7.6 \times 10^{-11}\right), P D C D 1\left(F C=-6.2 ; p_{2 d i}=1.1 \times 10^{-6}\right)$, THEMIS $(F C=-3.8 ; p$ $\left.=2.7 \times 10^{-165}\right)$ adj TBX21 $\left(F C=-2.1 ; p_{\text {adj }}=3.3 \times 10^{-25}\right)$.

Conclusion: LncRNAs are emerging as important regulators of immune function with increasing evidence of autoimmune disease relevance. Here, we leveraged RNA-seq, extensive bioinformatic data, and CRISPR technology to identify and functionally characterize LINC01871 as a potential mediato of the dysregulated T cell inflammatory response pathways implicated in SS pathogenesis.

Disclosure of Interests: Michelle L Joachims: None declared, Bhuwan Khatri: None declared, Kandice L Tessneer: None declared, Anna M Stolarczyk: None declared, Graham B Wiley: None declared, Astrid Rasmussen Speakers bureau: Novartis, ThermoFischer, Joel Guthridge Grant/research suppor from: Xencor, Bristol Myers Squibb, DXterity, Judith A. James Grant/research support from: Progentec Diagnostics, Inc, Consultant of: Abbvie, Novartis Jannsen, R Hal Scofield Grant/research support from: Pfizer, Kathy L Sivils: None declared, Indra Adrianto: None declared, Christopher Lessard: None declared

DOI: 10.1136/annrheumdis-2020-eular.3950

OP0141

\section{HIGH DIMENSIONAL ANALYSIS REVEAL A NETWORK OF CERTAIN TRANSCRIPTION FACTORS THAT LINK VASCULOPATHY AND ORGAN FIBROSIS IN SYSTEMIC} SCLEROSIS

C. G. Anchang ${ }^{1}$, B. Matalobos Lawaree ${ }^{1}$, S. Weber ${ }^{1}$, S. Rauber ${ }^{1}$, T. Wohlfahrt ${ }^{1}$, M. Luber ${ }^{1}$, A. Kreuter ${ }^{2}$, G. Schett ${ }^{1}$, J. Distler ${ }^{1}$, A. Ramming ${ }^{1} .{ }^{1}$ Department of Internal Medicine 3 - Rheumatology and Immunology, Friedrich-Alexander University (FAU) Erlangen-Nürnberg and Universitätsklinikum Erlangen, Erlangen, Germany; ${ }^{2}$ Department of Dermatology, Venereology and Allergology, HELIOS St. Elisabeth Klinik Oberhausen, University Witten- Herdecke, Oberhausen, Germany, Oberhausen, Germany

Background: Since vascular manifestations such as Raynaud's phenomenon often precede the onset of other clinical manifestations of systemic sclerosis (SSc), the identification of pathways linking vasculopathy to organ fibrosis might thus provide important insights into early disease mechanisms and allow early targeted intervention for both fibrotic and vascular events.

Objectives: In this study we performed high dimensional (HD) analyses to identify mediators that link vasculopathy to organ fibrosis.

Methods: HD techniques including RNA-seq, ChIP-seq, ATAC-seq and FISH-seq have been performed to identify mediators in vessels and fibrotic lesions of human skin samples of SSc patients and healthy volunteers. In addition, murine skin and lung tissue samples were analyzed by multi-channel immunofluorescence (IF) and confocal laser scanning microscopy. Microvascular endothelial cells, smooth muscle cells and fibroblasts have been further processed to address their functional attributes with regard to their proliferative, migratory and chemotactic capacity. In vivo models and ex vivo mouse fetal metatarsal assays were performed to study fibrotic and angiogenic processes

Results: Bioinformatic HD analyses revealed the ETS transcription factor PU.1 as molecular checkpoint of a network of factors that drive matrix production and fibrotic imprinting in SSc. Within this network ATF3 was significantly upregulated in fibroblasts of skin biopsies of SSc patients and of various organs of fibrosis models. ATF3 deficiency ameliorated fibrosis in various mouse models. Notably, ATF3 was significantly upregulated in vascular cells of fibrotic tissues of SSc patients. Multi-channel IF and confocal laser scanning microscopy of skin and lung biopsies of SSc patients revealed an increased expression of ATF3 especially in microvascular endothelial cells and smooth muscle cells. ATF3 overexpression in smooth muscle cells led to an extensively enhanced proliferation and increased migratory capacity whereas endothelial cells showed a SSc-like phenotype with reduced proliferation and migration. After ATF3 overexpression, tube formation capacity was completely altered as assessed by cumulative tube length, tube numbers and capillary sprouting. To investigate vessel outgrowth from a different perspective, we used the ex vivo fetal mouse metatarsal assay. ATF3 knockout mice showed a completely altered angiogenic response as assessed by tube length, number of branches and number junctions compared to wildtype controls

Conclusion: We identified PU.1 and ATF3 as key factors in disturbed vasculature and endogenous activated fibroblasts suggesting this axis as a potentia therapeutic target intervening both fibrotic and vascular manifestations.

Disclosure of Interests: Charles Gwellem Anchang: None declared, Bettina Matalobos Lawaree: None declared, Stefanie Weber: None declared, Simon Rauber: None declared, Thomas Wohlfahrt: None declared, Markus Luber: 